\title{
Analysis of the Output Ripple of the DC-DC Boost Charger for Li-Ion Batteries
}

\author{
Van-Sang Nguyen", Van-Long Tran", Woojin Choi ${ }^{\dagger}$, and Dae-Wook Kim ${ }^{* *}$ \\ ${ }^{*}$ Dept. of Electronic Eng., Soongsil University, Seoul, Korea \\ ${ }^{* *}$ Dept. of Economics, Soongsil University, Seoul, Korea
}

\begin{abstract}
In the design of battery chargers, limiting the output ripple current according to the manufacturer's recommendation is important for reliable service and extended battery life. Ripple components can cause internal heating of the battery and thus reduce the service life of the battery. Care must be exerted in the design of the switching converter for the charge application through the accurate estimation of the output current ripple value. This study proposes a method to reduce the output current ripple of the converter and presents a detailed analysis of the output current ripple of the DC-DC boost converter to provide a guideline for the design of the battery charger.
\end{abstract}

Keywords: Battery Charger, Li-Ion Battery, Output Current Ripple, Output Inductor

\section{INTRODUCTION}

Understanding battery-charging fundamentals and system requirements allows designers to select a suitable linear or switch-mode charging topology and optimize battery performance in the application. The battery-charging system is often provided low priority, particularly in cost-sensitive applications. However, the quality of the charging system plays a key role in the life and reliability of the battery.

Designers must be familiar with the fundamental requirements for charging lithium-ion (Li-ion) batteries to develop an optimized charging system for such batteries. The voltage regulation tolerance on the voltage applied to the cell should be higher than $\pm 1 \%$ as recommended by the battery manufacturer to maximize the performance of $\mathrm{Li}$-ion batteries. The preferred charge algorithm for $\mathrm{Li}$-ion batteries is a constant current-constant voltage (CC-CV) algorithm. In this method, charging is typically terminated by a minimum-charge current. The minimum current approach monitors the charge current during the constant-voltage stage and terminates the charge when it diminishes in the range of $0.02 \mathrm{C}$ to $0.07 \mathrm{C}[1]-[3]$. This condition implies that the

\footnotetext{
Manuscript received Jul. 23, 2013; revised Nov. 3, 2013

Recommended for publication by Associate Editor Dehong Xu.

${ }^{\dagger}$ Corresponding Author: cwj777@ssu.ac.kr

Tel: +82-2-820-0652, Fax: +82-2-817-7961, Soongsil University

*Dept. of Electrical Engineering, Soongsil University, Korea

*** Dept. of Economics, Soongsil University, Korea
}

output current ripple should not exceed this value. Although the magnitude of the ripple component in the output current is important for reliable performance and extended battery life, this component is often overlooked in the charger design.

Most of the chargers developed by far utilize buck-type converters that can step down the high AC voltage from the utility to a suitable level of DC for the load. Given that these buck-type converters have inductors at their output, current control can be performed easily and the output ripple requirements can be satisfied without any difficulty. However, in some applications with a low voltage DC source (e.g., fuel cells), a boost-type charger can provide a better solution because the source voltage can be lower than that of the battery. Although a buck-type converter with a transformer can also be an option for this type of application, it is unlikely to be selected if compactness and weight are considered, particularly for the charger of a portable electronic device.

Figs. 1(a) and 1(b) show several types of conventional DC-DC converters, such as the non-isolated boost converter, fly-back converter, buck-boost converter, and SEPIC converter, that have similar output structures with a pure resistive load and a battery, respectively. Given that the topologies have a front-end inductor and an output diode, the output current is not continuous; thus, the output ripple current is significantly larger than that of the buck-type topologies that have an output inductor. When the load is purely resistive, most of the ripple current can be filtered by the output capacitor as shown in Fig. 2(a). However, this 


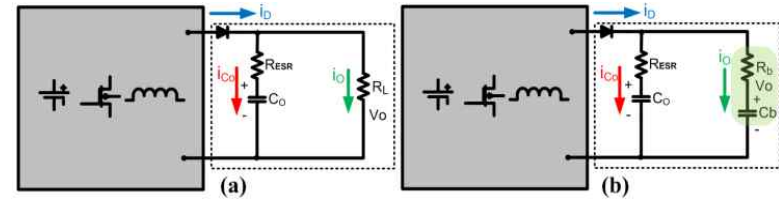

Fig. 1. Conventional converter topologies that have similar output structures. (a) With pure resistive load. (b) With a battery model.

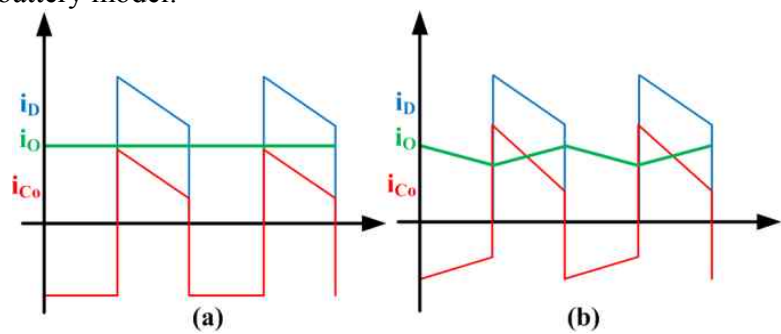

Fig. 2. Diode current, output current, and capacitor current of the converter shown in Fig. 1. (a) With pure resistive load. (b) With a battery model.

condition is no longer valid when the load is a battery because most of the current ripple may flow through the battery due to the huge capacitance in its equivalent circuit as shown in Fig. 2(b). This situation has to be considered to guarantee the reliable operation of the battery. The current ripple flowing into the battery during charging can generate heat owing to the interaction with the internal resistance of the battery $\left(\mathrm{I}^{2} \mathrm{R}\right.$ losses). This heat adds to the internal heat generated inside the battery. Thus, the excessive ripple current reduces the service life of the battery. Care must be exerted in designing the converter for the charger to meet the ripple requirements of the battery [5], [6].

A method to reduce the output current ripple of the DC-DC boost converter is proposed in this study and the output current ripple of the converter is analysed. The design method and the optimal selection of the inductor and capacitor at the output are also discussed in detail.

\section{DESIGN OF THE OUTPUT INDUCTOR AND CAPACITOR FOR THE PROPOSED NON-ISOLATED BOOST CONVERTER}

The proposed method for the reduction of the output ripple component can be simply implemented by adding another inductor between the output capacitor and the battery as shown in Fig. 3.

In this approach, an additional inductor is placed between the output capacitor and the battery to reduce the output ripple. Selecting the suitable value for the inductor and the capacitor at the output is necessary to meet the ripple requirements of the battery.

As shown in Fig. 2(b), the capacitor current waveform of the non-isolated boost converter can be drawn (see Fig. 4)

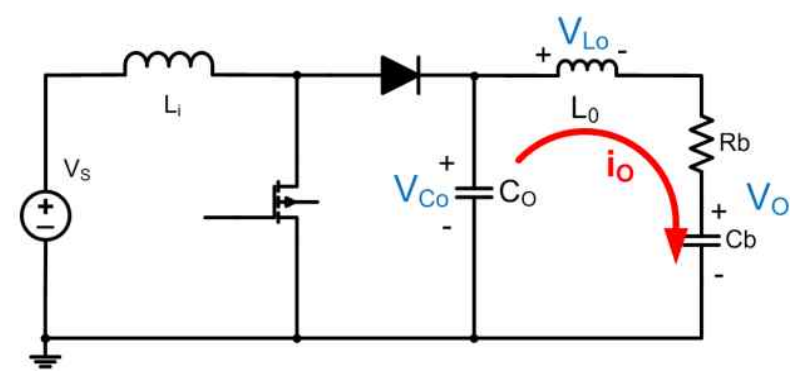

Fig. 3. Non-isolated boost converter with an additional inductor at the output.

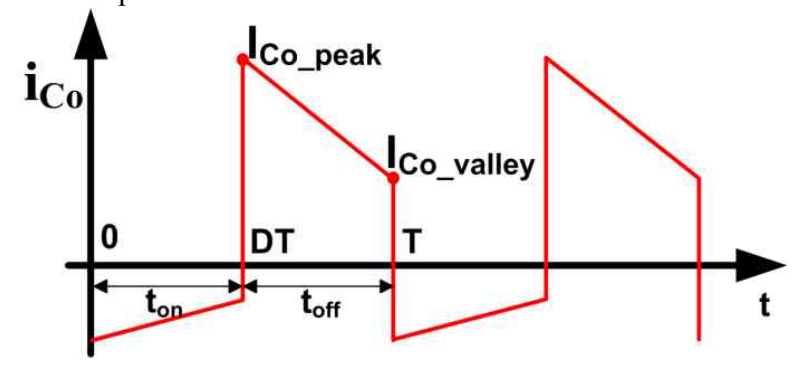

Fig. 4. Current waveform of the output capacitor in Fig. 3.

when the load is a battery and can be mathematically expressed by Equation (1) as a function of time bound between $D T$ and $T$.

$$
i_{C_{O}}(t)=\Delta i_{C_{O}} \frac{t_{\text {on }}-t}{t_{\text {off }}}+I_{C_{O_{-}} \text {peak }}(D T<t<T)
$$

where:

$$
\Delta i_{C_{O}}=\left(I_{C_{O_{-}} \text {peak }}-I_{C_{O_{-}} \text {valley }}\right)
$$

The voltage of the output capacitor can be obtained by the intergration of $i_{C o}(t)$ as in Equation (3), and the voltage variation at the capacitor can then be expressed as Equation (4).

$$
\Delta v_{C_{O}}=\frac{1}{C_{O}} \int_{D T}^{T}\left[\Delta i_{C_{O}} \frac{t_{\text {on }}-t}{t_{\text {off }}}+I_{C_{O_{-}} \text {peak }}\right] d t=\frac{1}{C_{O}} I_{O} D T
$$

The voltage on the output inductor can then be expressed as Equation (5) ( $\triangle I_{O}$ is the output ripple current).

$$
\Delta v_{L_{O}}=\left.L_{O} \frac{d\left(\Delta i_{O} \frac{t_{\text {on }}-t}{t_{\text {off }}}+I_{O_{-} \text {peak }}\right)}{d t}\right|_{D T} ^{T}=\frac{L_{O} \Delta i_{O}}{(1-D) T}
$$

The output current ripple can be expressed as Equation (5) by using Equations (3), (4), and KVL.

$$
\Delta i_{O}=\frac{1}{L_{O} C_{O}} I_{O} D(1-D) T^{2}-\Delta v_{O} \frac{(1-D) T}{L_{O}}
$$

Equation (5) shows the relationship between the output ripple and the reactive components at the output. However, numerous pairs of the values for the output inductor (Lo) and the output capacitor $(\mathrm{Co})$ can satisfy the equation. Thus, 


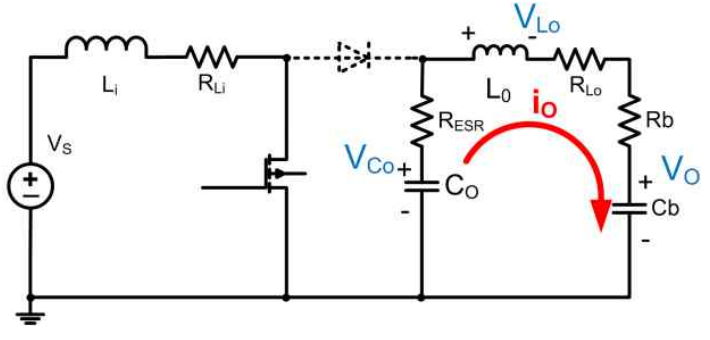

Fig. 5. Equivalent circuit of the proposed boost converter when the switch is closed.

another condition that represents the relationship between the inductor and the capacitor is necessary to decide the values.

In-depth circuit analysis is required to derive the equation for the relationship between the output ripple value and the reactive components at the output.

\section{Circuit ANALYSIS FOR THE PROPOSED CONVERTER TO EVALUATE THE MAGNITUDE OF THE OUTPUT RIPPLE CURRENT}

Steady state analysis is performed when the switch is closed to analyze the output ripple current of the proposed boost converter. For accurate circuit analysis, all the parasitic components are considered as shown in Fig. 5.

The voltage loop equation in the rear-end subcircuit when the switch is closed can be expressed as Equation (6).

$$
\frac{1}{\mathrm{C}_{O}} \int_{0}^{T} i_{C_{O}} d t+R_{E S R} i_{C_{O}}=L_{O} \frac{d i_{O}}{d t}+R_{L_{O}} i_{O}+R_{b} i_{O}+\frac{1}{C_{b}} \int_{0}^{T} i_{O} d t
$$

Given the huge capacitance value in the battery model (typically several thousands of farad in case of the Li-ion battery) compared with the output capacitor value, the variation in the battery voltage during the switch-off period can be neglected. Thus, we obtain

$$
\frac{1}{C_{O}} \int_{0}^{T} i_{O} d t+L_{O} \frac{d i_{O}}{d t}+\left(R_{b}+R_{L_{O}}+R_{E S R}\right) i_{O}=0 \quad\left(\because C_{b} \gg \mathrm{C}_{O}\right)
$$

Differentiating the above equation and dividing both sides by $\mathrm{L}_{\mathrm{O}}$ yield the second-order differential equation as Equation (8)

$$
\begin{array}{ll}
\text { where: } & \frac{d^{2} i_{0}}{d t^{2}}+\frac{R_{\text {parasitic }}}{L_{0}} \frac{d i_{0}}{d t}+\frac{1}{C_{0} L_{0}} i_{0}=0 \\
& R_{\text {parasitic }}=R_{b}+R_{L_{0}}+R_{\mathrm{C}_{0}}
\end{array}
$$

The characteristic equation of the second-order differential equation is

$$
s^{2}+2 \alpha s+\omega_{O}^{2}=0
$$

where:

$$
\left(\alpha=\frac{R_{\text {parasitic }}}{2 L_{O}} \text { and } \omega_{O}=\frac{1}{\sqrt{C_{O} L_{O}}}\right)
$$

The damping factor $(\zeta)$ can be expressed as Equation (10).

$$
\zeta=\frac{\alpha}{\omega_{0}}=\frac{R_{\text {parasitic }}}{2} \sqrt{\frac{C_{0}}{L_{0}}}
$$

Given the solution obtained from Equation (8), the output current may have three different forms depending on the value of the damping factor.

When the damping factor is less than $1(\zeta<1)$, the circuit response is under-damped and the output current can be expressed as Equation (11).

$$
i_{O}(t)=A e^{-\alpha t} \sin \left(\omega_{d} t+\varphi\right)
$$

where: $\omega_{d}=\sqrt{\omega_{O}^{2}-\alpha^{2}}$.

When the damping factor is equal to $1(\zeta=1)$, the circuit response is critically damped and the output current can be expressed as Equation (12).

$$
i_{O}(t)=B_{1} t e^{-\alpha t}+B_{2} e^{-\alpha t}
$$

When the damping factor is larger than $1(\zeta>1)$, the circuit response is over-damped and the output current can be expressed as Equation (13).

$$
i_{O}(t)=C_{1} e^{-\omega_{O}\left(\zeta+\sqrt{\zeta^{2}-1}\right) t}+C_{2} e^{-\omega_{O}\left(\zeta-\sqrt{\zeta^{2}-1}\right) t}
$$

Equations (11), (12), and (13) must be solved under the initial conditions to derive the equation for the output current at each case.

During the period when the switch is closed, voltage loop Equation (6) can be rewritten as Equation (14).

$$
-\left.\left(\Delta v_{C_{O}}+\Delta v_{R_{E S R}}\right)\right|_{0} ^{D T}=\left.\left(\Delta v_{L_{O}}+\Delta v_{R_{L_{O}}}+\Delta v_{C_{b}}+\Delta v_{R_{b}}\right)\right|_{0} ^{D T}
$$

\section{A. Under-damped Case}

As shown above, the output current can be expressed as Equation (11) when the switch is closed and can be rewritten as Equation (15), including average output current $\mathrm{I}_{\mathrm{O}}$.

$$
i_{O}(t)=\frac{\Delta i_{O}}{2} e^{-\alpha t} \sin \left(\omega_{d} t+\varphi\right)+I_{O}
$$

At least two conditions are required to determine the magnitude of output ripple current $\Delta i_{O}$ and phase $\varphi$ in Equation (15). Thus, the equations for the initial and final values of the output current must be derived when the switch is closed.

Fig. 6 shows the equivalent circuit of the proposed boost converter when the switch is open. By applying KVL to this circuit, we obtain

$$
-V_{S}+L_{i} \frac{d i_{i}}{d t}+R_{L_{i}} i_{i}+L_{O} \frac{d i_{O}}{d t}+R_{L_{O}} i_{O}+R_{b} i_{O}=0
$$




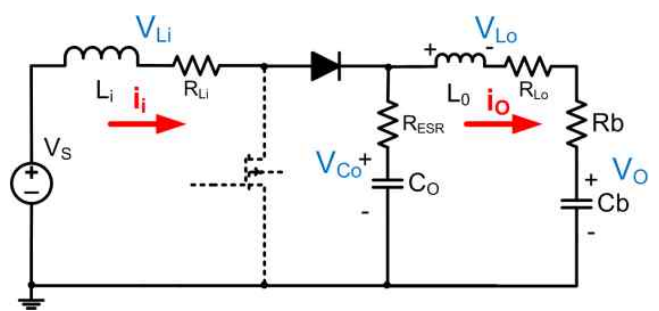

Fig. 6. Equivalent circuit of the proposed boost converter when the switch is open.

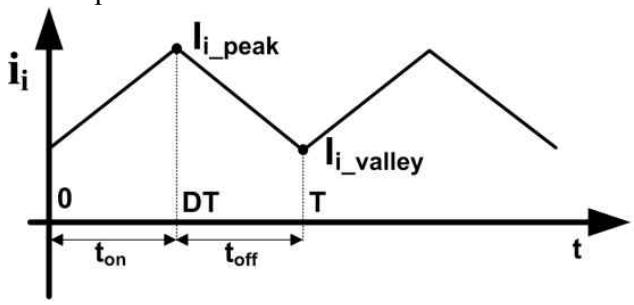

Fig. 7. Front-end inductor current waveform of the proposed boost converter.

Fig. 7 shows the waveform of the front-end inductor current of the boost converter. The waveform can be expressed as Equation (17).

$$
i_{i}(t)=\Delta i_{i} \frac{t_{o n}-t}{t_{o f f}}+I_{i_{-} p e a k} \because D T<t<T
$$

With Equations (16) and (17), the first-order differential equation of the output current can be obtained as Equation (18).

$$
L_{O} \frac{d i_{O}}{d t}+\left(R_{L_{O}}+R_{b}\right) i_{O}-V_{S}-L_{i} \frac{\Delta i_{i}}{t_{\text {off }}}+R_{L_{i}}\left(\Delta i_{i} \frac{t_{\text {on }}-t}{t_{\text {off }}}+I_{i_{-} \text {peak }}\right)=0
$$

Thus, the expression for the output current when the switch is open can be obtained as Equation (19) by solving Equation (18).

$$
\begin{aligned}
i_{O_{-} \text {open }}= & \frac{R_{L_{i}} \Delta i_{i}}{t_{\text {off }}}\left(\frac{t}{R_{L_{O}}+R_{b}}-\frac{1}{\left(R_{L_{O}}+R_{b}\right)^{2}}\right)+ \\
& \frac{V_{S}+L_{i} \frac{\Delta i_{i}}{t_{\text {off }}}-R_{L_{i}} I_{i_{-} \text {peak }}-R_{L_{i}} \Delta i_{i} \frac{D}{1-D}}{R_{L_{O}}+R_{b}}+e^{-\left(R_{L_{O}}+R_{b}\right) t}
\end{aligned}
$$

Therefore, the output current at $\mathrm{t}=\mathrm{DT}$ and $\mathrm{t}=\mathrm{T}$ can be expressed as Equations (20) and (21), respectively.

$$
\begin{gathered}
I_{O_{-} \text {open } \_1}(t=D T)=\frac{R_{L_{i}} \Delta i_{i}}{(1-D) T}\left(\frac{D T}{R_{L_{o}}+R_{b}}-\frac{1}{\left(R_{L_{o}}+R_{b}\right)^{2}}\right)+ \\
\frac{V_{S}+L_{i} \frac{\Delta i_{i}}{(1-D) T}-R_{L_{i}} I_{i_{-} \text {peak }}-R_{L_{i}} \Delta i_{i} \frac{D}{1-D}}{R_{L_{o}}+R_{b}}+e^{-\left(R_{L_{O}}+R_{b}\right) D T}
\end{gathered}
$$

$$
\begin{gathered}
I_{O_{-} \text {open_2 }}(t=T)=\frac{R_{L_{i}} \Delta i_{i}}{(1-D) T}\left(\frac{T}{R_{L_{O}}+R_{b}}-\frac{1}{\left(R_{L_{o}}+R_{b}\right)^{2}}\right)+ \\
\frac{V_{S}+L_{i} \frac{\Delta i_{i}}{(1-D) T}-R_{L_{i}} I_{i_{-} \text {peak }}-R_{L_{i}} \Delta i_{i} \frac{D}{1-D}}{R_{L_{o}}+R_{b}}+e^{-\left(R_{L_{O}}+R_{b}\right) T}
\end{gathered}
$$

where:

$$
\left(\Delta i_{i}=\frac{V_{S} D T}{L_{i}} \text { and } I_{i_{-} \text {peak }}=\frac{I_{O}}{1-D}+\frac{V_{S} D T}{2 L_{i}}\right) .
$$

The initial and final values of the front-end inductor current when the switch is open are similar to its final and initial values when the switch is closed as shown in Fig. 7. Thus, we obtain

$$
\begin{aligned}
& I_{O}(t=0)=I_{O_{-} o p e n \_2} \\
& I_{O}(t=D T)=I_{O_{-} o p e n \_1}
\end{aligned}
$$

By using this relationship and substituting the initial conditions of Equation (22) into (15), the magnitude of the output ripple current in the under-damped case can be expressed as Equation (23).

$$
\Delta i_{O}=2 \sqrt{\begin{array}{l}
\left\{\frac{1}{\sin \left(\omega_{d} D T\right)}\left[\begin{array}{l}
\frac{I_{O_{-} \text {open } 1}-I_{O}}{e^{-\alpha D T}} \\
-\cos \left(\omega_{d} D T\right)\left(I_{O_{-} \text {open_2 } 2}-I_{O}\right)
\end{array}\right]\right\}^{2} \\
+\left(I_{O_{-} \text {open } 2}-I_{O}\right)^{2}
\end{array}}
$$

\section{B. Critically Damped Case}

The output current of the proposed converter in the critically damped case can be expressed as Equation (12) when the switch is closed and can be rewritten as Equation (24), including average output current $\mathrm{I}_{\mathrm{O}}$.

$$
i_{O}(t)=B_{1} t e^{-\alpha t}+B_{2} e^{-\alpha t}+I_{O}
$$

Equation (24) shows that the output current reaches the maximum value at $\mathrm{t}=0$ and the minimum value at $\mathrm{t}=\mathrm{DT}$. Hence, the maximum and minimum values of the output ripple current can be expressed as Equations (25) and (26), respectively.

$$
\begin{gathered}
B_{1}=-\frac{\Delta i_{O}}{2 D T}\left(1+e^{\frac{R_{\text {parasitic }} D T}{2 L_{O}}}\right) \\
B_{2}=\frac{\Delta i_{O}}{2}
\end{gathered}
$$

During the switch-on time, the variation in the voltage on the output capacitor and its effective series resistance (ESR) can be calculated as Equations (27) and (28), respectively. 


$$
\begin{gathered}
\Delta v_{C_{O}}=\frac{1}{C_{O}} \int_{0}^{D T} i_{O} d t=\left.\frac{1}{C_{O}}\left\{\left[B_{1} \frac{(-\alpha t-1) e^{-\alpha t}}{\alpha^{2}}-\frac{B_{2} e^{-\alpha t}}{\alpha}\right]+I_{O} t\right\}\right|_{0} ^{D T} \\
=B_{1} \frac{(-\alpha D T-1) e^{-\alpha D T}+1}{C_{O} \alpha^{2}}-\frac{B_{2} e^{-\alpha D T}}{C_{O} \alpha}+\frac{I_{O} D T}{C_{O}} \\
\left.\Delta V_{R_{E S R}}\right|_{O} ^{D T}=\Delta i_{O} R_{E S R}
\end{gathered}
$$

The voltage at the output inductor can be expressed as Equation (29).

$$
v_{L_{O}}=L_{O} \frac{d i_{O}}{d t}=L_{O} \frac{d\left(B_{1} t e^{-\alpha t}+B_{2} e^{-\alpha t}+I_{O}\right)}{d t}
$$

Thus, the voltage variation on the output inductor between $\mathrm{t}=0$ and $\mathrm{t}=$ DT can be derived as Equation (30).

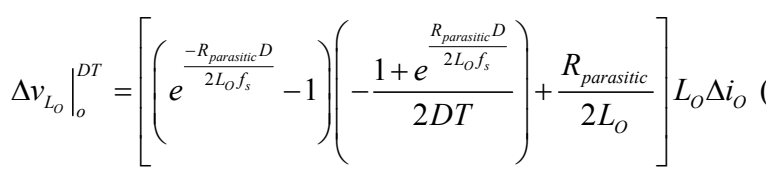

The voltage variation on the parasitic components between $\mathrm{t}=0$ and $\mathrm{t}=\mathrm{DT}$ can be expressed as Equations (31), (32), and (33).

$$
\begin{gathered}
\left.\Delta v_{R_{L_{O}}}\right|_{o} ^{D T}=\Delta i_{O} R_{L o} \\
\left.\Delta v_{R_{b}}\right|_{o} ^{D T}=\Delta i_{O} R_{b} \\
\Delta v_{C_{b}}=0\left(\because C_{b} \text { is huge }\right)
\end{gathered}
$$

The voltage variation on the capacitance of the battery can be neglected given the huge capacitance of the battery.

With Equations (14) and (27)-(33), the output ripple current in the critically damped case can be expressed as Equation (34).

$$
\Delta i_{O}=\frac{I_{O} D T}{\left[\left(J_{1}-J_{2}\right)+R_{\text {parasitic }}\right] C_{O}}
$$

where:

$$
\begin{gathered}
J_{1}=\left[\left(e^{-\alpha D T}-1\right)\left(-\frac{1+e^{\alpha D T}}{2 D T}\right)+\alpha\right] L_{O} \\
J_{2}=\frac{1}{C_{O}}\left[-\frac{1+e^{\alpha D T}}{2 D T} \frac{\left\{(-\alpha D T-1) e^{-\alpha D T}+1\right\}}{\alpha^{2}}-\frac{e^{-\alpha D T}}{\alpha}\right]
\end{gathered}
$$

\section{Over-damped Case}

The output current of the proposed converter in the overdamped case can be expressed as Equation (37) when the switch is closed. This equation shows that during such period, the output current reaches the maximum value when $t=0$ and the minimum value when $t=D T$.

$$
i_{O}(t)=D_{1} e^{-\omega_{0}\left(\zeta+\sqrt{\left.\zeta^{2}-1\right)} t\right.}+D_{2} e^{-\omega_{0}\left(\zeta-\sqrt{\zeta^{2}-1}\right) t}+I_{O}
$$

Considering that the maximum and minimum values of the output ripple current can be observed at $t_{1}=0$ and $t_{2}=D T$, the coefficients in Equation (37) can be expressed as Equations (38) and (39).

$$
\begin{gathered}
D_{1}=-\frac{e^{-\omega_{0}\left(\zeta-\sqrt{\zeta^{2}-1}\right) D T}+1}{e^{-\omega_{0}\left(\zeta+\sqrt{\zeta^{2}-1}\right) D T}-e^{-\omega_{0}\left(\zeta-\sqrt{\zeta^{2}-1}\right) D T}} \frac{\Delta i_{O}}{2} \\
D_{2}=\frac{e^{-\omega_{0}\left(\zeta+\sqrt{\zeta^{2}-1}\right) D T}+1}{e^{-\omega_{0}\left(\zeta+\sqrt{\zeta^{2}-1}\right) D T}-e^{-\omega_{0}\left(\zeta-\sqrt{\zeta^{2}-1}\right) D T}} \frac{\Delta i_{O}}{2}
\end{gathered}
$$

During the switch-on time between $\mathrm{t}=0$ and $\mathrm{t}=\mathrm{DT}$, the variation in the voltage on the output capacitor and its ESR can be calculated as Equations (40) and (41), respectively.

$$
\begin{aligned}
& \Delta v_{C_{O}}= \frac{1}{C_{O}} \int_{0}^{D T} i_{O} d t \\
&= \frac{1}{C_{O}}\left(\begin{array}{c}
\left.\frac{K_{1}}{-\omega_{0}\left(\zeta+\sqrt{\zeta^{2}-1}\right)}\left(e^{-\omega_{0}\left(\zeta+\sqrt{\zeta^{2}-1}\right) D T}-1\right)+\right) \\
\frac{K_{2}}{\omega_{0}\left(\zeta-\sqrt{\zeta^{2}-1}\right)}\left(e^{-\omega_{0}\left(\zeta-\sqrt{\zeta^{2}-1}\right) D T}-1\right)
\end{array}\right) \Delta i_{O}+\frac{I_{o} D T}{C_{O}}(40) \\
&\left.\Delta v_{R_{E S R}}\right|_{O} ^{D T}=\Delta i_{O} R_{E S R}
\end{aligned}
$$

The voltage at the output inductor can be expressed as Equation (42).

$v_{L_{O}}=L_{O} \frac{d i_{O}(t)}{d t}=L_{O} \frac{d\left(D_{1} e^{-\omega_{0}\left(\zeta+\sqrt{\zeta^{2}-1}\right) t}+D_{2} e^{-\omega_{0}\left(\zeta-\sqrt{\left.\zeta^{2}-1\right)} t\right.}+I_{O}\right)}{d t}$

Thus, the voltage variation on the output inductor between $\mathrm{t}=0$ and $\mathrm{t}=\mathrm{DT}$ can be derived as Equation (43).

$\left.\Delta v_{L_{O}}\right|_{O} ^{D T}=-L_{O}\left[\begin{array}{l}\omega_{0}\left(\zeta+\sqrt{\zeta^{2}-1}\right) D_{1}\left(e^{-\omega_{0}\left(\zeta+\sqrt{\zeta^{2}-1}\right) D T}-1\right) \\ +D_{2} \omega_{0}\left(\zeta-\sqrt{\zeta^{2}-1}\right)\left(e^{-\omega_{0}\left(\zeta-\sqrt{\zeta^{2}-1}\right) D T}-1\right)\end{array}\right]$

The voltage variation on the parasitic components between $\mathrm{t}=0$ and $\mathrm{t}=$ DT can be expressed as Equations (44), (45), and (46).

$$
\begin{gathered}
\left.\Delta v_{R_{L_{O}}}\right|_{o} ^{D T}=\Delta v_{O} R_{L o} \\
\left.\Delta v_{R_{b}}\right|_{o} ^{D T}=\Delta i_{O} R_{b} \\
\Delta v_{C_{b}}=0\left(\because C_{b} \text { is huge }\right)
\end{gathered}
$$


With Equations (14) and (40)-(46), the output ripple current in the critically damped case can be expressed as Equation (47).

$$
\Delta i_{O}=\frac{I_{O} D T}{\left(\Psi_{1}-\Psi_{2}+R_{\text {parasitic }}\right) C_{O}}
$$

where:

$$
\begin{gathered}
\Psi_{1}=-L_{O}\left(\begin{array}{l}
\omega_{O}\left(\zeta+\sqrt{\zeta^{2}-1}\right) K_{1}\left(e^{-\omega_{O}\left(\zeta+\sqrt{\zeta^{2}-1}\right) D T}-1\right) \\
+K_{2} \omega_{O}\left(\zeta-\sqrt{\zeta^{2}-1}\right)\left(e^{-\omega_{O}\left(\zeta-\sqrt{\zeta^{2}-1}\right) D T}-1\right)
\end{array}\right) \\
\Psi_{2}=\frac{1}{C_{O}}\left(\begin{array}{l}
\frac{K_{1}}{-\omega_{O}\left(\zeta+\sqrt{\zeta^{2}-1}\right)}\left(e^{-\omega_{O}\left(\zeta+\sqrt{\zeta^{2}-1}\right) D T}-1\right) \\
+\frac{K_{2}}{\omega_{O}\left(\zeta-\sqrt{\zeta^{2}-1}\right)}\left(e^{-\omega_{O}\left(\zeta-\sqrt{\zeta^{2}-1}\right) D T}-1\right)
\end{array}\right) \\
K_{1}=-\frac{1}{2} \frac{e^{-\omega_{O}\left(\zeta-\sqrt{\zeta^{2}-1}\right) D T}+1}{e^{-\omega_{O}\left(\zeta+\sqrt{\zeta^{2}-1}\right) D T}-e^{-\omega_{O}\left(\zeta-\sqrt{\zeta^{2}-1}\right) D T}} \\
K_{2}=\frac{1}{2} \frac{e^{-\omega_{O}\left(\zeta+\sqrt{\zeta^{2}-1}\right) D T}+1}{e^{-\omega_{O}\left(\zeta+\sqrt{\zeta^{2}-1}\right) D T}-e^{-\omega_{O}\left(\zeta-\sqrt{\zeta^{2}-1}\right) D T}}
\end{gathered}
$$

Using the equations derived above for the magnitude of the output ripple current in the three different cases results in Equations (23), (34), and (47).

\section{Simulation Results ANd Optimal VAlues FOR THE REACTIVE COMPONENTS}

The proposed DC-DC boost charger is designed with the specifications in Table I and simulated with PSIM to verify the circuit analysis and derivations. Several pairs of the inductance and capacitance values are selected to represent each case according to the value of $\zeta$.

The proposed boost charger charges the Li-ion battery pack at $\mathrm{CC} / \mathrm{CV}$ charge mode with $4 \mathrm{~A}(0.8 \mathrm{C})$ charge current and $12.6 \mathrm{~V}$ charge voltage until the charge current decreases by $0.52 \mathrm{~A}(0.1 \mathrm{C})$, in which the battery is assumed to be fully charged. As shown in Equations (23), (34), and (47), the output current ripple is directly proportional to the charge current, which means that the output current ripple has the largest value in the $\mathrm{CC}$ charge mode. The $\mathrm{L}-\mathrm{C}$ filter is then designed with the charge current rate condition to satisfy the output current ripple during the entire charging period.

As shown in Fig. 8, the output currents show three different waveforms for each case. The output current varies from its maximum value to the minimum value during the switch-on time in the critically damped and over-damped cases as expected. The values of the output current ripple for each case calculated with Equations (23), (34), and (47) are

\begin{tabular}{|c|c|c|}
\hline Input voltage & $\mathrm{V}_{\mathrm{i}}$ & $6-9 \mathrm{~V}$ \\
\hline Output voltage & $\mathrm{V}_{\mathrm{O}}$ & $12.6 \mathrm{~V}$ \\
\hline Output power & $\mathrm{P}_{\mathrm{O}}$ & $50 \mathrm{~W}$ \\
\hline Frequency & $\overline{f_{s}}$ & $60 \mathrm{kHz}$ \\
\hline Input inductor & $\mathrm{Li}$ & $32 \mu \mathrm{H}$ \\
\hline Capacitor & $\mathrm{C}_{\mathrm{O}}$ & $\begin{array}{l}30 \mu \mathrm{F}- \\
4000 \mu \mathrm{F}\end{array}$ \\
\hline Output inductor & $\mathrm{L}_{\mathrm{O}}$ & $10 / 20 \mu \mathrm{H}$ \\
\hline Specification of the battery & \multicolumn{2}{|c|}{ Li-Ion Battery Pack (3S2P) } \\
\hline Nominal current & $\mathrm{I}_{\text {nominal }}$ & $5.2 \mathrm{~A}(1 \mathrm{C})$ \\
\hline Charging current & $\mathrm{I}_{\mathrm{O}}$ & $4 \mathrm{~A}(0.8 \mathrm{C})$ \\
\hline Charging voltage & $\mathrm{V}_{\mathrm{O}}$ & $12.6 \mathrm{~V}$ \\
\hline Battery initial voltage & $\mathrm{V}_{\mathrm{b}}$ & $10.8 \mathrm{~V}$ \\
\hline Output ripple current & $\Delta \mathrm{I}_{\text {output_ripple }}$ & $\begin{array}{l}0.26 \mathrm{~A} \\
(0.05 \mathrm{C})\end{array}$ \\
\hline $\begin{array}{c}\text { Equivalent capacitance } \\
\text { of the battery }\end{array}$ & $\mathrm{C}_{\mathrm{b}}$ & $9660 \mathrm{~F}$ \\
\hline $\begin{array}{c}\text { Equivalent series resistance } \\
\text { of the battery }\end{array}$ & $\mathrm{R}_{\mathrm{b}}$ & $0.3 \Omega$ \\
\hline
\end{tabular}
$86 \mathrm{~mA}, 43 \mathrm{~mA}$, and $29 \mathrm{~mA}$, respectively; the values are close to those in the PSIM simulation results.
TABLE I

SYSTEM PARAMETERS

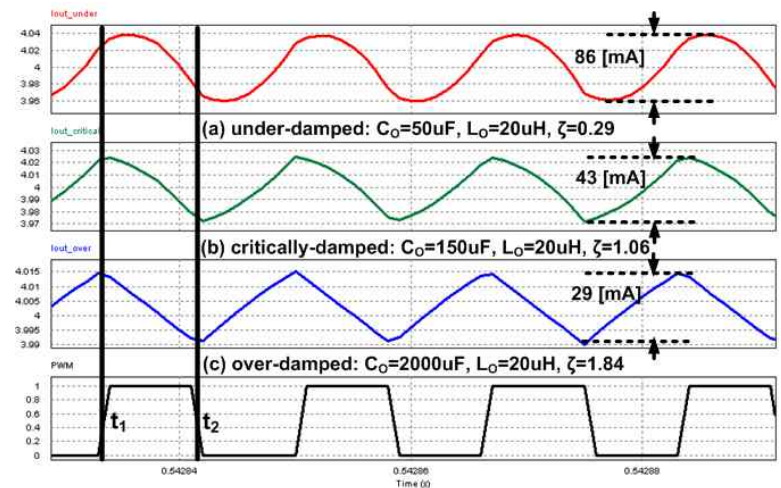

Fig. 8. Waveforms of the output current ripple for the three different cases.

As previously mentioned, numerous pairs of the inductance and capacitance values can satisfy the ripple requirements. Optimal sizing of the reactive components in terms of cost and size is thus necessary in the design of the converter.

An $\mathrm{L}-\mathrm{C}$ filter with a variable range for the capacitor and inductor is designed to verify the effect of the filter on the output current ripple in the three cases. Fig. 9 shows the output current ripple values for the 18 different pairs of the inductance and capacitance values of the proposed boost charger at each case based on the calculated and PSIM simulation results, which are well matched. As shown in the figure, when the reactive components are selected to satisfy the under-damped case, the size of the reactive components may be relatively small, whereas the output current ripple is much larger than that in the critically damped case. When the reactive components are selected to satisfy the over-damped 


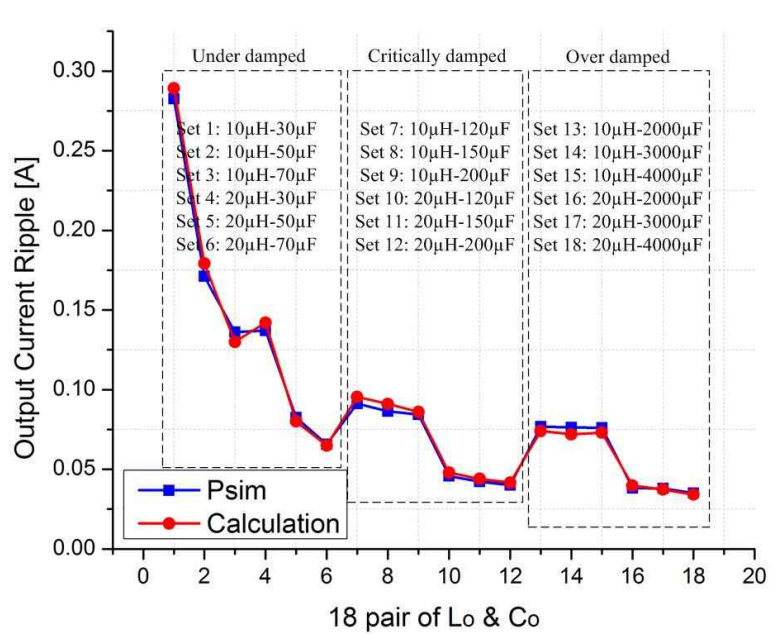

Fig. 9. Output current ripple simulation results by using PSIM and results of the calculations using Equations (23), (34), and (47) for the 18 pairs of $L_{o}$ and $C_{o}$.

case, the output current ripple is not smaller than that in the critically damped case; however, the reactive components are much larger in size. Thus, based on these results, optimal selection can be made with the pair of reactive components in the critically damped case because this pair offers better attenuation for the output current ripple than that in the under-damped case and is better in terms of size and cost than that in the over-damped case.

Fig. 9 also shows the effect of the inductance and capacitance values on the output current ripple. The output current ripple is significantly changed by a small variation value of the output inductor, whereas the value of capacitance change only slightly affects the output current ripple. In the design of the proposed boost converter, a small output inductor can significantly reduce the output current ripple and in turn, minimize the size of the output capacitor.

Given that the critically damped case provides optimal results, the relationship between the inductance and capacitance values can be obtained with Equation (10) and $\zeta$ $=1$. By using this relationship and Equation (5), the ouput inductor and output capacitor values can be obtained with Equations (52) and (53), respectively.

$$
\begin{gathered}
C_{O}=\frac{2(1-D) T\left(\sqrt{\left.\Delta v_{O}^{2}+\frac{\Delta i_{O} I_{O} D R_{\text {parasitic }}^{2}}{(1-D)}-\Delta v_{O}\right)}\right.}{\Delta i_{O} R_{\text {parasitic }}^{2}} \\
L_{O}=\frac{R_{\text {parasitic }}^{2}}{4} \frac{2(1-D) T\left(\sqrt{\Delta v_{O}^{2}+\frac{\Delta i_{O} I_{O} D R_{\text {parasitic }}^{2}}{(1-D)}}-\Delta v_{O}\right)}{\Delta i_{O} R_{\text {parasitic }}^{2}}
\end{gathered}
$$

Thus, if the current ripple limitation of the battery and the converter specifications, such as switching frequency, duty

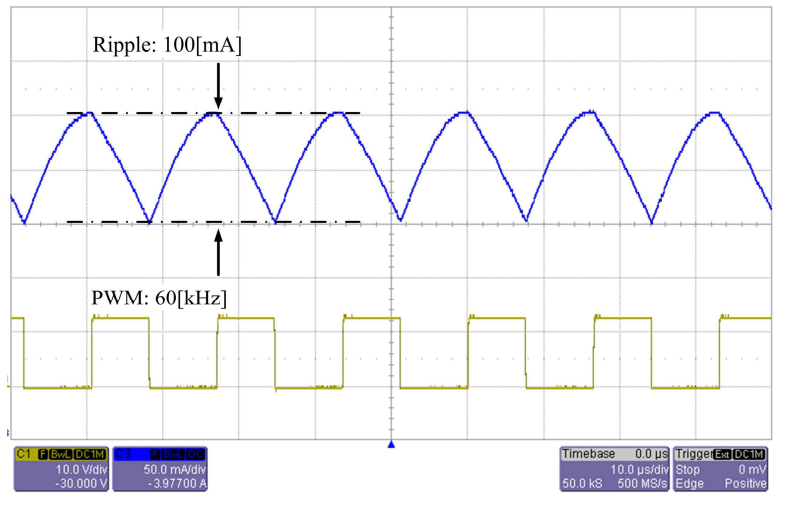

Fig. 10. Output current waveform and PWM signal for the under-damped case with $\mathrm{L}_{\mathrm{O}}=20 \mu \mathrm{H}, \mathrm{C}_{\mathrm{O}}=50 \mu \mathrm{F}, \zeta=0.29$.

cycle, and the parasitic components values in the circuit, are known, then the reactive component values of the converter can be calculated.

\section{EXPERIMENTAL RESULTS}

A $50 \mathrm{~W}$ boost charger based on the specifications in Table I is proposed to validate the analysis of the output ripple discussed in the previous section. The maximum allowable current ripple is $5 \%$ of the rated charge current as specified in Table I. The waveform of the output current ripple and its magnitude are verified with a $3 \mathrm{~S} 2 \mathrm{P}$ Li-ion battery pack for a laptop computer. During charging, the battery parameters change slightly because of the limited range of the battery temperature, that is, from $30^{\circ}$ to $40^{\circ}$.

Figs. 10, 11, and 12 show the output current waveforms of the proposed boost charger for the three different cases. The selected reactive components are similar in each case as shown in Fig. 8. The magnitude of the output current ripple in the three cases is close to that in the calculation and simulation values. All the errors are less than $10 \%$; however, the error is slightly larger than $10 \%$ in the under-damped case because of the error values of the experimental capacitor, inductor, and parasitic resistor. The error in the capacitance value significantly affects the ripple in the under-damped case as shown in Fig. 9. The simulation and experimental output current waveforms in the critically damped and over-damped cases match well as shown in Figs. 8, 11, and 12. However, a slight difference exists between the simulation and experimental waveforms in the under-damped case as shown in Figs. 8 and 10. The difference is caused by the small variation in the battery parameters during charging, which is associated with the large current ripple in this case.

\section{CONCLUSIONS}

In this study a topological method was developed to reduce the output current ripple in the boost charger and the output current ripple was analysed. Given that the output 


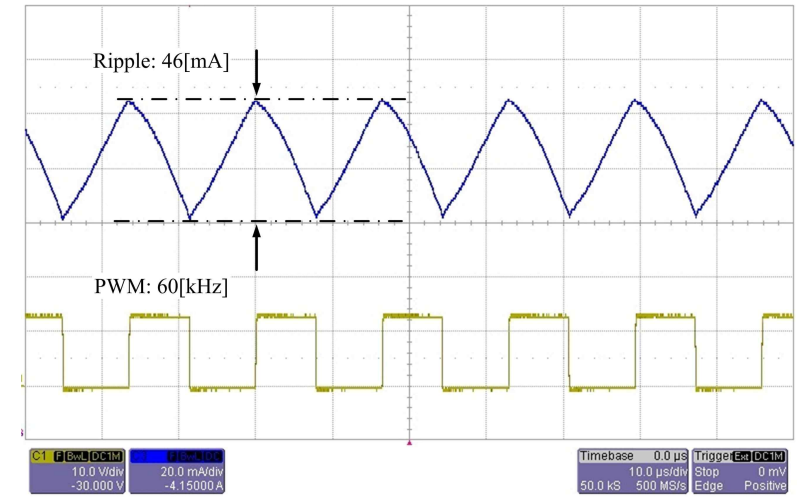

Fig. 11. Output current waveform and PWM signal for the critically-damped case with $\mathrm{L}_{\mathrm{O}}=20 \mu \mathrm{H}, \mathrm{C}_{\mathrm{O}}=150 \mu \mathrm{F}, \zeta=1.06$.

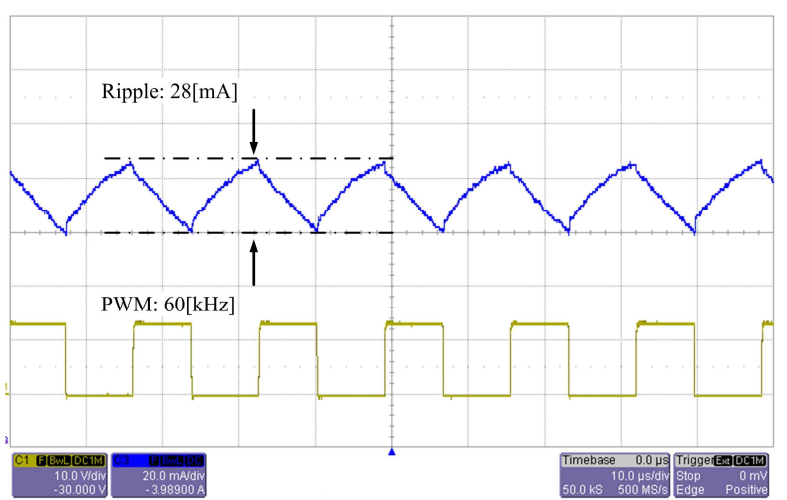

Fig. 12. Output current waveform and PWM signal for the over-damped case with $\mathrm{L}_{\mathrm{O}}=20 \mu \mathrm{H}, \mathrm{C}_{\mathrm{O}}=2000 \mu \mathrm{F}, \zeta=1.84$.

ripple of the charger is an extremely sensitive factor, care was exerted in the design of the charger. The equations for the optimal selection of the output inductor and output capacitor values were derived for the suitable design of the boost charger. The proposed method and analysis can be utilized to improve the design of the boost converter for battery charge applications, thereby guaranteeing the service life of the battery.

\section{ACKNOWLEDGEMENTS}

This work was supported by the Soongsil University Research Fund (2010).

\section{REFERENCES}

[1] V. Vorpérian, "A ripple theorem for PWM DC-to-DC converters operating in continuous conduction mode," IEEE 35th Annual Power Electronics Specialists Conference, pp. 28-35, 2004.

[2] C. Liu, J-S. Lai, "Low frequency current ripple reduction technique with active control in a fuel cell power system with inverter load," IEEE Trans. Power Electron., Vol. 22, No. 4, pp. 1429-1436, Jul. 2007.

[3] J-M. Kwon, E-H. Kim, B-H. Kwon, K-H. Nam, "High-efficiency fuel cell power conditioning system with input current ripple reduction," IEEE Trans. Ind. Electron., Vol. 56, No. 3, pp. 826-834, Mar. 2009.
[4] T. Shimizu, Y. Jin, and G. Kimura, "DC ripple current reduction on a single-phase PWM voltage-source rectifier," IEEE Trans. Ind. Appl., Vol. 36, No. 5, pp. 1419-1429, Sep./Oct. 2000.

[5] D. Dujic, M. Jones, and E. Levi, "Analysis of output current ripple RMS in multiphase drives using space vector approach," IEEE Trans. Power Electron., Vol. 24, No. 8, pp. 1926-1938, Aug. 2009.

[6] V. S. Nguyen and W-J. Choi, "A non-isolated boost charger for the Li-Ion battery suitable for fuel cell powered laptop computer," 7th International Power Electronics and Motion Control Conference (IPEMC), Vol. 2, pp. 946-951, 2011.

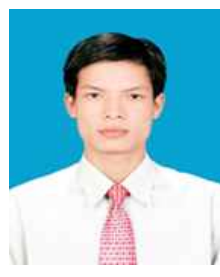

Van-Sang Nguyen was born in Hanoi, Vietnam, in 1985. He received his B.S. degree in electrical engineering from Hanoi University of Science and Technology, Hanoi, Vietnam, in 2008. He is currently pursuing his M.S. degree at Soongsil University, Seoul, Republic of Korea. His research interests include battery chargers and $\mathrm{DC}-\mathrm{DC}$ converters

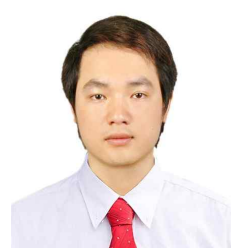

Van-Long Tran was born in Haiphong, Vietnam, in 1988. He received his B.S. degree in electrical engineering from Hanoi University of Science and Technology, Hanoi, Vietnam, in 2011. He is currently pursuing his M.S. degree at Soongsil University, Seoul, Republic of Korea. His and $\mathrm{DC}-\mathrm{DC}$ converters. research interests include battery chargers

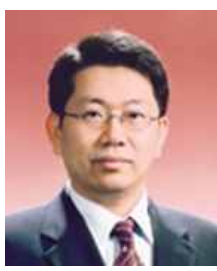

Woojin Choi was born in Seoul, Republic of Korea, in 1967. He received his B.S. and M.S. degrees in electrical engineering from Soongsil University, Republic of Korea, in 1990 and 1995, respectively. He received his $\mathrm{Ph} . \mathrm{D}$. degree in electrical engineering from Texas A\&M University, USA, in 2004. He worked with Daewoo Heavy Industries as a research engineer from 1995 to 1998. In 2005, he joined the School of Electrical Engineering, Soongsil University. His research interests include modeling and control of electrochemical energy sources such as fuel cells, batteries, and supercapacitors, power conditioning technologies in renewable energy systems, and DC-DC converters for fuel cells and hybrid electric vehicles.

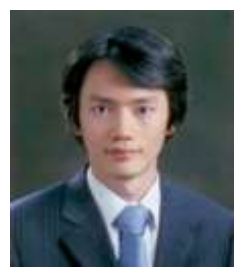

Dae-Wook Kim was born in Seoul, Republic of Korea, in 1973. He received his B.A. degree in Economics from Yonsei University, Republic of Korea, in 1999. He received his Ph.D. degree in economics from the University of California at Davis, USA, in 2004. He worked for Korea Institute for Industrial Economics and Trade as a research fellow from 2004 to 2007. In 2007, he joined the Department of Economics, Soongsil University. His current research interests include energy economics, particularly market structure and competition in energy industries. 